\title{
ACESSO À JUSTIÇA: DIRETRIZES PARA ALCANÇÁ-LO EM MATÉRIA PENAL
} ACCESS TO JUSTICE: GUIDELINES TO ACHIEVE IT IN THE CRIMINAL FIELD

\author{
${ }^{1}$ Rejane Alves de Arruda \\ ${ }^{2}$ Angela Jank Calixto
}

\section{Resumo}

O presente artigo tem por objetivo apresentar algumas diretrizes para se alcançar o acesso à justiça em matéria penal. A partir do método de pesquisa bibliográfica, exploratória e descritiva, verificou-se a diferença entre "acesso à justiça" e "acesso ao Judiciário" e quais são os principais obstáculos para alcançar aquele primeiro. Concluiu-se que os métodos alternativos de solução de conflitos, a adoção de procedimento específico para causas de particular importância social, assim como a consagração dos princípios da oralidade e da intervenção mínima constituem ferramentas importantes para se alcançar o acesso à justiça na esfera criminal, desde que previstas em lei.

Palavras-Chave: Acesso à justiça; métodos alternativos; procedimento especial; oralidade; intervenção mínima.

\begin{abstract}
This article intends to present some guidelines to achieve access to justice in the criminal field. From an exploratory, descriptive and bibliographical review, the difference between the concept of "access to justice" and "access to the courts" and the main obstacles to achieve the first one were verified. It was found that alternative methods of conflict resolution, the adoption of a specific procedure for causes with particular social importance, as well as the consecration of the principles of orality and minimal intervention are important tools to achieve access to justice in the criminal sphere as long as established by law.
\end{abstract}

Keywords: Access to justice; alternative methods; special procedure; orality; minimal intervention.

\footnotetext{
${ }^{1}$ Doutora e Mestre em Direito pela Pontifícia Universidade Católica, PUCSP - SP. Professora da Universidade Federal do Mato Grosso do Sul, UFMS - MS, (Brasil), e Universidade Católica Dom Bosco, UCDB, Campo Grande - MS, (Brasil). Advogada.

${ }^{2}$ Mestranda em Direitos Humanos pela Universidade Federal do Mato Grosso do Sul, UFMS - MS, (Brasil).Email: angelajcalixto@gmail.com
} 


\section{INTRODUÇÃO}

O acesso à justiça pressupõe não somente que o Estado garanta aos indivíduos a prestação da tutela jurisdicional, mas também que resolva os litígios que surgem entre particulares de forma individual e socialmente justa. Sua ampliação e aprimoramento no âmbito da tutela penal são imprescindíveis para se viabilizar o acesso de todos a uma ordem jurídica justa e eficiente.

Atualmente, visando garantir a eficaz prestação jurisdicional no âmbito penal, procura-se desenvolver mecanismos para se superar obstáculos e empecilhos, tais como os custos do processo e a alta exigência de formalismo, entre outros, que dificultam o acesso dos particulares à justiça, esta concebida como uma virtude a ser buscada.

Propõe-se, nesse sentido, a instauração de métodos alternativos de resolução de conflitos, a instituição de um procedimento judicial diferenciado para as causas de particular importância social, com o fim de se obter uma mais rápida resolução do litígio, e a adoção de princípios diferenciados em causas de importância particular, para otimizar a atividade do Estado enquanto titular do direito de punição.

Dessa forma, procura-se com este trabalho, por meio de uma pesquisa bibliográfica, exploratória e descritiva, demonstrar como tais mecanismos constituem ferramentas importantes para se alcançar o acesso à justiça na esfera criminal.

Para se atingir tal objetivo, discorrer-se-á, em um primeiro momento, acerca do conceito de acesso à justiça e de que forma esta se diferencia do simples acesso à jurisdição. Após, serão analisados os fatores que obstam o devido acesso à justiça e de que forma eles constituem grandes empecilhos ou barreiras à adequada prestação jurisdicional. Por fim, adentrar-se-á mais especificamente no tema, sendo apresentadas as diretrizes para se alcançar o efetivo acesso à justiça em matéria penal.

\section{ACESSO À JUSTIÇA}

Consoante a lição lapidar de São Tomás, "a essência da justiça consiste em dar a outrem o que lhe é devido, segundo uma igualdade". Trata-se de um sentido estrito e próprio, pelo qual justiça designa uma virtude (MONTORO, 1978, p. 162). 
Numa acepção objetiva, pode ainda significar a própria legislação - porque assegura o direito de cada um - ou os órgãos ou o Poder encarregado de sua aplicação. Refere-se, então, à ordem social que garante a cada um o que lhe é devido(MONTORO, 1978, p. 157).

A variedade de significações do termo justiça não nos isenta de definir os contornos da expressão "acesso à Justiça". Pode-se dizer, a partir de uma mescla entre as concepções objetiva e subjetiva, que o acesso à justiça implica num sistema estatal pelo qual as pessoas podem reivindicar seus direitos e/ou resolver seus litígios, produzindo resultados que sejam individual e socialmente justos (CAPPELLETTI, 1988, p. 8).

$\mathrm{O}$ acesso à justiça importará na possibilidade de se resolver os conflitos existentes no corpo social, por meio de uma intervenção do Estado que, a despeito de impedir a autotutela ou a justiça com as próprias mãos, coloca, à disposição dos cidadãos, instrumentos e serviços que atendam suas demandas e, principalmente, correspondam às expectativas sociais.

Não é à toa que Marco Antônio Marques da Silva aponta a existência de dois aspectos fundamentais no problema de acesso à justiça no Brasil: a questão da necessidade de que o cidadão possa chegar até o Poder Judiciário, ou seja, fazer valer o seu direito de acesso à justiça, e como esta demanda será absorvida e eficazmente atendida pelo Poder Judiciário (SILVA, 2001, p. 96).

Assim, pode-se constatar uma distinção entre "acesso à justiça" e "acesso ao Judiciário". Entende-se que o acesso ao Judiciário está resguardado com o direito de petição, elencado no art. 5o, inciso XXXIV, $a$, da CF/88, e com o princípio da inafastabilidade da jurisdição, também insculpido no art. 5o, porém no inciso XXXV, da Carta Magna, relacionando-se mais de perto com o direito de ação.

No que se refere ao acesso à justiça, o enfoque passa da iniciativa da demanda para o resultado dela, pressupondo não só a efetiva prestação da tutela jurisdicional, mas, principalmente, um decisum que atenda, concretamente, a conotação que o termo "justiça", como virtude, impõe.

Daí porque Kazuo Watanabe (1988, p. 128-135) adverte: “a problemática do acesso à Justiça não pode ser estudada nos acanhados limites do acesso aos órgãos judiciais já existentes. Não se trata apenas de possibilitar o acesso à Justiça enquanto instituição estatal, e sim de viabilizar o acesso à ordem jurídica justa”. 


\section{ObSTÁCUlos A SEREM TRANSPOSTOS PARA O EFETIVO ACESSO À JUSTIÇA}

Em teoria geral, Antônio Carlos de Araújo Cintra, Ada Pellegrini Grinover e Cândido Rangel Dinamarco (1994, p. 34-35) apontam alguns óbices que ameaçam a efetividade do processo. São empecilhos que vão da admissão da ação e seu desenvolvimento até a qualidade das decisões judiciais proferidas.

Dentre os "pontos sensíveis" - como são chamados por eles - estão as dificuldades econômicas que impedem ou dificultam a demanda ou uma defesa adequada, a necessidade de um devido processo legal participativo, bem como a importância da utilidade e da justiça do provimento jurisdicional.

Apesar de reconhecida a diferença entre acesso à jurisdição e acesso à justiça, os entraves apontados pelos ilustres mestres não deixam de demonstrar a preocupação de que o processo seja efetivamente um instrumento de promoção de justiça, fato que, inclusive, autoriza o entendimento de que ambas as expressões sejam tomadas como sinônimas (PORTANOVA, 2002, p. 112).

Contudo, não se pode dizer que todo acesso à justiça passe necessariamente pelo acesso à jurisdição, uma vez que existem formas extrajudiciais de resolução de conflitos que, colocadas à disposição daqueles interessados, evitam a intervenção estatal. Tais instrumentos são utilizados, na maior parte das vezes, em contendas ocorridas no âmbito do direito privado e envolvem interesses em regra disponíveis.

Portanto, o campo de incidência desses meios alternativos não é ilimitado, encontrando fronteiras, principalmente, na seara penal, na qual a intervenção do Estado demonstra-se imprescindível. A adoção do princípio "nulla poena sine judicium" demonstra claramente a verdade desta afirmação.

Pelo sistema processual penal, o Estado, por ser sempre sujeito passivo da infração praticada e titular do jus puniendi, avoca para si a atividade de "dar a cada qual o que lhe pertence" e exige que esta tarefa se torne cumprida a partir dos instrumentos por ele disponibilizados e segundo os critérios por ele determinados.

Como a responsabilidade criminal culmina numa sanção, o devido processo legal clássico é o instrumento utilizado para sua apuração, concedendo uma série de garantias às partes que dele participam. Automaticamente, a exigência de tal procedimento acaba por conferir-lhe uma carga muito grande responsabilidade, pois, passando a ser único caminho 
para a solução de conflitos, pressupõe um combate eficaz dos obstáculos que impedem o acesso à justiça.

Tais obstáculos, quais sejam, o custo do processo, o tempo de duração o formalismo e as condições das partes, merecem um estudo mais aprofundado, passando-se a demonstrar em que aspecto eles impedem o adequado acesso do jurisdicionado à justiça.

\subsection{Custo}

Como primeiro obstáculo ao acesso à Justiça tem-se o custo da demanda.

Não se refere, aqui, exclusivamente às custas processuais que envolvem as remunerações dos atos praticados no processo, mas inclui também despesas com honorários advocatícios e o dispêndio do próprio Estado com a estrutura e instalações de prédios e com o pagamento de salários aos sujeitos processuais e auxiliares da justiça.

O processo, como instrumento de prestação da tutela jurisdicional e acesso à justiça, envolvendo a prática de um conjunto de atos, não só reclama uma dotação orçamentária do ente público, mas também conta com as partes para a arrecadação de fundos que auxiliem na manutenção e funcionamento do aparato jurisdicional.

$\mathrm{Na}$ seara criminal, o encargo das partes de arcar com as custas está previsto no art. 806 do CPP, que prevê que a sentença ou acórdão que julgar a ação, incidente ou recurso, condenará nas custas o vencido. Nas ações penais privadas, permite o CPP a cobrança de custas no transcorrer do processo, inclusive para as despesas referentes aos atos requeridos pelo querelado (art. 806, CPP).

Em que pesem a gratuidade assegurada ao hipossuficiente e a assistência judiciária prestada pela Defensoria Pública aos necessitados, sabe-se que as partes não estão livres de outros dispêndios no desenvolvimento da demanda. Além disso, para os mais abastados, é inegável que a burocracia para recolhimento de custas e preparo, assim como a demora nos cálculos, constitui fator de prolongamento do litígio. Por outro lado, o Estado nem sempre coloca à disposição da coletividade uma estrutura adequada e um número suficiente de servidores preparados e gabaritados para atender as necessidades da prestação jurisdicional e os anseios daqueles que a requerem.

No cenário dessa realidade, como lembrou Cappelletti (1988, p. 19), as pequenas causas acabam sendo as mais prejudicadas. Se o litígio tiver de ser decidido por processos 
judiciários formais, os custos podem exceder o montante da controvérsia, ou, se isso não acontecer, podem consumir o conteúdo a ponto de tornar a demanda uma futilidade.

Com efeito, embora o processo penal não envolva interesses de natureza patrimonial e não apresente custas que guardam uma relação direta com um respectivo valor da causa, não se pode desconsiderar que a gravidade da infração é fator primordial na determinação do interesse da parte em buscar as instâncias judiciais - tanto assim que os crimes mais graves são apurados mediante ação penal pública, ou seja, são objeto de um procedimento cuja iniciativa compete ao Ministério Público, não estando à mercê da vontade da vítima. Em infrações de menor lesividade, muitas vezes, o ofendido pode deixar de levar ao conhecimento da autoridade policial ou judicial o cometimento do fato, justamente por não dispor de recursos financeiros para arcar com as despesas que podem gerar um processo, banalizando seus interesses em prol da reserva econômica.

A partir dessas considerações, pode-se inferir que o custo que permeia a atividade jurisdicional e que é arcado pelo Estado e pelas partes constitui uma barreira que não pode ser esquecida na implementação de medidas que visem a ampliar e, principalmente, otimizar o acesso à justiça.

\subsection{Tempo}

Se o conflito entre o jus puniendi e o status libertatis do agente infrator deve ser resolvido, em regra, no processo penal clássico, e este se manifesta por meio de uma série de atos que devem ser praticados numa sequência lógica e determinada pelos sujeitos processuais, torna-se inegável a influência que o fator tempo possa ter no movimento de acesso à justiça.

Tal influência pode ser sentida pelo réu que espera, o quanto antes, a decisão da causa e que, enquanto esta não é proferida, suporta uma prisão provisória e a pecha de estar sendo processado; pela vítima que, além de almejar uma sentença que reconheça seu direito à reparação do dano ex delicto, anseia por uma resposta justa e necessária àquele que transgrediu normas penais de convivência; enfim, e principalmente, pela coletividade que se aflige com a criminalidade, teme a impunidade e aspira uma segurança jurídica.

Ainda que reconhecida a famosa advertência, atribuída ao antigo Conselheiro De La Bruyere, de que a demora na administração da justiça constitui, na verdade, pura denegação dela (TUCCI, 1997, p. 15), em matéria criminal existe ainda a agravante da prescrição que 
acaba por fulminar o direito de punir do Estado caso este não promova, dentro de certo lapso temporal, providências indispensáveis para responsabilizar o autor da infração penal praticada.

Assim, considerando que o processo é um instrumento destinado à atuação da lei, deve ele, na medida do possível, desenvolver-se mediante um procedimento célere, a fim de que a tutela jurisdicional emerja realmente oportuna e efetiva. Tanto é que se afirma correntemente que os direitos subjetivos dos cidadãos devem ser providos da máxima garantia social, com o mínimo sacrifício da liberdade individual e, ainda, com o menor dispêndio de tempo e de energia (TUCCI, 1997, p. 27).

Como não pode haver automatismo, o importante, então, é que se abrevie, o máximo possível, o tempo entre a lesão do direito e a sentença (TUCCI, 1997, p. 27), rumo a uma decisão que seja, a um só tempo, rápida e segura. Os efeitos da delonga processual são desastrosos para as partes, pois, além de desestimulá-las, aumenta os custos e pressiona os economicamente fracos a abandonar suas causas (CAPPELLETTI, 1988, p. 20).

Portanto, procedimentos céleres e que visem uma resposta ou solução breve tendem a contribuir para que a resposta estatal atenda prontamente o interesse das partes que litigam, evitando o descrédito e o desgaste do Poder Judiciário.

\subsection{Formalismo}

Outro obstáculo que se pode apontar como sendo uma barreira de acesso à Justiça, necessariamente ligado ao retardamento da prestação jurisdicional, refere-se ao formalismo encartado em alguns dos procedimentos disponibilizados pelo Poder Judiciário para solução de conflitos. A prática de muitos atos processuais, num procedimento caracterizado pela desconcentração de suas fases, acaba por ensejar uma indesejável demora na resolução da lide.

Com efeito, como lembrou Cappelletti (1988, p. 24), os litígios formais são considerados pouco atraentes - procedimentos complicados, formalismo, ambientes que intimidam, como o dos tribunais, juízes e advogados, figuras tidas como opressoras, fazem com que o litigante se sinta perdido, um prisioneiro num mundo estranho. $\mathrm{O}$ excesso de solenidades tende a desmotivar o interessado, fazendo com que o direito de ação chegue a ser 
um verdadeiro ônus (NALINI, 1994, p. 43), ante os inúmeros inconvenientes de uma demanda.

A ideia que surge, então, é de simplificação - um ponto de referência para aqueles que já optaram, em vários sistemas, pela "fuga do procedimento ordinário" e descobriram a necessidade e importância do desdobramento para procedimentos sumários e especiais abreviados (BATISTA; FUX, 2001, p. 22) - da aplicação do direito abstrato aos casos concretos, quer na quantidade, quer na qualidade dos meios empregados para a solução da lide, sem burocracia (MIRABETE, 2002, p. 35).

Não propugna, com isso, a exclusão de formalidades legais, pois se reconhece que a sua rigidez constitui uma garantia contra o arbítrio do juiz ou da parte mais forte da relação processual, sendo imprescindível nas hipóteses em que se discutem interesses de significativa importância. Ademais, a demora no procedimento tende a ser uma garantia de maior amplitude de cognição e defesa de direitos em juízo.

Contudo, com base num critério de proporcionalidade, cabe pensar seriamente na adoção de um sistema abreviado para causas menores, pelo qual se flexibilize a prática de alguns atos, sem comprometer a sua finalidade. Um procedimento caracterizado pela oralidade e concentração dos atos e pela homogeneização de prazos, que atenda, de forma célere, os pequenos interesses.

\subsection{Condições das Partes}

A par das barreiras referidas, outro obstáculo se revela ao acesso à Justiça: as condições das partes que estão em conflito e que, eventualmente, integrarão a relação jurídica processual. São características que abrangem desde a camada social na qual o particular se insere, até a consciência que possa ter do exercício de seus direitos.

Cappelleti (1988, p. 21-26) fala de vantagens e desvantagens de que possam gozar os litigantes de um processo, aludindo especificamente aos aspectos relacionados aos recursos financeiros de que dispõem, a aptidão para reconhecerem um direito e atuarem numa demanda, assim como a própria proximidade que possam ter com o sistema judicial, por serem litigantes habituais ou eventuais.

Reporta-se a algumas particularidades que possam ensejar dificuldades no acesso à Justiça, como: a) os embaraços que envolvem as condições pessoais de fortuna das partes; b) os empecilhos relativos à capacidade de reconhecer a existência de direitos juridicamente 
exigíveis, ante a falta de estudo ou informação; c) incômodos referentes à falta de disposição psicológica ou de habilidade para enfrentar os desgastes de uma demanda, como, por exemplo, nos casos de vítimas de violência conjugal ou sexual; d) a própria descrença no processo como forma de resolução de conflito e, acima de tudo, como instrumento de promoção de justiça, face a uma experiência frustrante, própria ou de terceiro, com as instâncias judiciais.

Nota-se que tais obstáculos se referem às partes e guardam uma relação direta com o subjetivismo de cada uma delas, tornando-as, potencialmente, sujeitos processuais distintos, com anseios e expectativas próprias. Buscar uma igualdade é utopia, pois tais diferenças jamais poderão ser erradicadas (CAPPELLETTI, 1988, p. 15). Resta-nos, então, verificar quais as barreiras que podem ser efetivamente atacadas rumo à garantia de acesso à justiça.

\section{DIRETRIZES PARA SE ALCANÇAR O EFETIVO ACESSO À JUSTIÇA EM MATÉRIA PENAL}

Apontadas as principais barreiras que impedem o acesso à Justiça, passa-se a formular algumas diretrizes que, uma vez adotadas, poderão derrubá-las e, assim, contribuir para a satisfação da demanda de justiça dos cidadãos em matéria penal.

Não existe a pretensão de se pôr fim a todos os obstáculos existentes, pois se reconhece que alguns são instransponíveis - principalmente os relativos às partes - e outros somente a médio ou longo prazo serão resolvidos. Todavia, a dinâmica da realidade não concede o privilégio de cruzar os braços, já que os conflitos se multiplicam diariamente e continuam exigindo soluções rápidas e, como é obvio, justas.

Enumeram-se alguns caminhos a serem trilhados.

\subsection{Métodos alternativos de resolução de conflitos.}

É sabido que o processo é o instrumento colocado à disposição das partes para a resolução de conflitos e se desenvolve por meio de uma série de atos que, numa ordem certa e determinada, permitem o conhecimento e, consequentemente, o julgamento do fato pelo Judiciário. Constatou-se, ainda, que fatores como o tempo, custo e formalismo, fazem parte da mesma realidade, pois estão presos à ideia de procedimento, pelo qual a prática de atos 
solenes é, em regra, obrigatória (formalismo), envolve certa duração (tempo) e pressupõe um custo.

Assim, propõe-se a adoção de métodos alternativos de resolução de conflitos pelos quais se rompe o mito do monopólio estatal da jurisdição. Trata-se dos chamados sucedâneos da jurisdição ou equivalentes jurisdicionais, ou seja, de meios pelos quais se pode atingir a composição da lide, por obra dos próprios litigantes ou de um particular desprovido de poder jurisdicional (ALVIM, 2000, p. 49).

Segundo Miranda Rosa (Apud MORAES, 1991, p. 69), tais vias informais podem enquadrar-se nas seguintes espécies: a) negociação direta; b) mediação ou conciliação e c) arbitramento.

Entre as formas de negociação direta, que também é denominada de autocomposição, encontra-se a desistência (renúncia à pretensão), o reconhecimento (reconhecimento expresso da procedência da ação) e a transação (fato jurídico através do qual as partes, mediante concessões recíprocas, previnem ou terminam o litígio).

Já a mediação e a conciliação constituem formas pelas quais o conflito é resolvido com a intermediação de terceiro, distinto dos litigantes, o qual tenta conduzi-los a um entendimento final. Enquanto na primeira, o mediador tenta aproximar os contendores promovendo o diálogo entre eles a fim de que encontrem uma solução e ponham termo ao conflito, na segunda o conciliador não só aproxima as partes, como ainda realiza atividades de controle das negociações, aparando as arestas porventura existentes e formulando propostas(FIGUEIRA JÚNIOR, 1999, p. 131).

O arbitramento, por sua vez, também chamado de arbitragem, juízo arbitral ou jurisdição privada, implica numa forma paraestatal de composição de controvérsia, em que a decisão é delegada a um particular que julga a lide (FIGUEIRA JÚNIOR, 1999, p. 123).

Embora possa parecer contraditório, tais alternativas de pacificação social, colocadas à disposição das partes, não têm um raio ilimitado de incidência, já que a solução de conflitos de natureza penal deve ser tarefa exclusiva do Estado, não se admitindo formas de negociação que não tenham a interferência direta e imediata do ente público. Tal fato, porém, não impede a adoção dos fundamentos da conciliação como forma de simplificar a aplicação da pena, desde que esta atividade continue nas mãos do Estado-Juiz.

Prestigiar a vontade das partes, concedendo-lhes a possibilidade de abrir mão de parte de suas pretensões, implica no reconhecimento de que a satisfação de direitos pode ser alcançada na própria relação - intra muros - não estando vinculada a formas rígidas ou a 
instrumentos determinados. Importa na conscientização popular de que a resolução de conflitos não decorre apenas de uma sentença judicial ou constitui necessariamente o resultado de uma demanda processual de vencedores e vencidos, mas é um objetivo que todos os cidadãos, por viverem em sociedade, esforçam-se para atingir.

Ademais, com a admissão de vias que prestigiem uma composição entre as partes, é possível chegar-se a uma pacificação social muitas vezes não alcançada pela sentença, uma vez que esta, limitando-se a ditar autoritariamente a regra para o caso concreto, acaba não sendo, em muitos casos, aceita de bom grado pelo vencido. Por isso mesmo foi salientado que a justiça tradicional se volta para o passado, enquanto a justiça informal se dirige ao futuro. A primeira julga e sentencia; a segunda compõe, concilia e previne situações de rupturas (GRINOVER, 1988, p. 283).

Assim, em matéria penal, o importante é que se elejam os casos nos quais será facultada a disponibilidade de direitos e garantias pelas partes, e em que medida isto ocorrerá. A disciplina legal do assunto torna-se imprescindível, pois, quando se admite a aplicação dos fundamentos da conciliação na esfera penal, a consensualidade que a legitima não é, e nem poderia ser, absoluta, posto que a tutela de direitos, pertencentes à comunidade, ainda continua sendo um escopo a ser alcançado, prioritariamente, pela atividade estatal. Mesmo porque o direito penal protege os bens jurídicos mais caros da sociedade, inclusive por meio da mais grave das sanções que é a pena, razão pela qual seria temerária a adoção de medidas cujos corolários recaíssem na exclusão da ingerência do Estado na solução dos conflitos dessa natureza.

Sob este norte, resta dizer que a introdução de princípios que prestigiem a conciliação no espaço de conflito não pode ser vista como um indício de desconfiança da atuação judicial ou dos provimentos jurisdicionais, mas como uma forma de priorizar, para o conhecimento e a árdua atuação do Judiciário, as questões com uma envergadura proporcional ao procedimento formal e dispendioso que será instaurado. Do mesmo modo, não pode a própria conciliação ser encarada como uma justiça de segunda classe, mas, pelo contrário, como um instrumento que pretende ser, nas palavras de Calamandrei (2003, p. 169-170), “um complemento útil da legalidade".

Daí o porquê da crença de que a adoção de mecanismos distintos de resolução de conflitos e, em especial na seara penal, de seus fundamentos, pode ser uma alternativa válida e eficaz para a efetivação e ampliação do acesso à Justiça. 
Neste contexto, nota-se que a Lei $n^{\circ} 9.099 / 95$, ao regular a estrutura e funcionamento dos Juizados Especiais Criminais, acabou por prever vários institutos que prestigiam o consenso entre os envolvidos. No art. 79 da referida lei, já foram elencadas duas formas de resolução de conflitos para as infrações penais de menor potencial ofensivo: a composição dos danos civis e a transação penal. No primeiro caso, busca-se a resolução da responsabilidade civil e, no segundo, da responsabilidade penal.

Por outro lado, no artigo 89, também da Lei $n^{\circ}$ 9.099/95, foi prevista a suspensão condicional do processo, proposta pelo Ministério Público nas infrações cuja pena mínima não seja superior a 1 (um) ano. Neste caso, obsta-se o andamento do processo penal, deixando o acusado sujeito ao cumprimento de várias obrigações por determinado período de tempo, após o qual será declarada extinta a punibilidade.

Em todos os casos, constata-se que o consenso entre as partes permeia os institutos penais adotados, sem se olvidar da intervenção estatal, obrigatória em matéria de direitos indisponíveis.

\subsection{Diferenciação de procedimento judicial para causas de particular importância social}

Dentre as barreiras que impedem o acesso à Justiça, apontamos o formalismo da maior parte dos procedimentos, colocados à disposição das partes pelo Poder Jurisdicional, para se alcançar a tutela de seus interesses. Vimos que o número de atos praticados, bem como a solenidade que os envolve, constitui um fator de desestímulo para aquele que, irrompendo as dificuldades da iniciativa da ação, aventura-se a percorrer a demanda.

Apesar de reconhecermos impossível a admissão de uma prestação jurisdicional livre de um processo com sistemática e métodos próprios, perfilhamos o entendimento de que possa existir uma diferenciação na forma de cada procedimento, uma flexibilização de regras e cânones baseada, principalmente, nas distinções de fundo que possam existir entre os fatos que lhes servem de objeto.

Com assento num critério de razoabilidade, propõe-se, então, que o Estado disponibilize duas espécies de procedimentos aos membros do corpo social: um que contenha disposições rígidas e formalidades essenciais, que se desenvolva de modo parcimonioso, apto a apurar fatos graves ou complexos e ensejar uma ampla colheita de provas, e outro que, baseado no critério de simplicidade, pressuponha tanto a presença de atos considerados essenciais, praticados de modo célere, quanto outros desenvolvidos de modo informal, 
visando a rápida solução do litígio. Trata-se, aqui, da adoção daquilo que Mauro Cappelletti (1988, p. 95) chamou de procedimentos especiais para solucionar "pequenas injustiças de grande importância social".

De fato. Não bastaria que reconhecêssemos a existência de causas de distintas densidades se não existisse a preocupação em disponibilizar-se procedimentos diferenciados para julgá-las. Seria o mesmo que reconhecer a importância de um fim, sem proporcionar os meios necessários para alcançá-lo. Ademais, o sistema processual tradicional, ideal para a discussão de questões complicadas, acaba por afugentar aqueles que contendem sobre pequenos interesses, justamente por não existir proporcionalidade entre a espécie de litígio e a duração, o custo e o formalismo do processo que será instaurado para resolvê-lo.

Afora o descaso aparentado, tal fato gera consequências nefastas para os membros da sociedade enquanto cidadãos, pois, além da descrença que passam a nutrir pelo Judiciário, são levados a banalizar direitos cuja discussão não exibe grande complexidade, mas cujo exercício é indispensável num estado democrático de direito. A refreada e constante insatisfação passam a permear as relações sociais, dando azo ao que Kazuo Watanabe (1985, p. 1-3) denominou de "litigiosidade contida".

Por isso falamos de "causas de particular importância social". Ainda que se refiram a conflitos de pequena gravidade, reduzido valor econômico ou mínima necessidade probatória, não podem ser desprezadas ou desconsideradas pelo Estado no exercício da tutela jurisdicional, uma vez que representam os primeiros e iniciais desequilíbrios das relações sociais.

A existência de um procedimento diferenciado para os pequenos litígios é imprescindível para que o ente público possa traduzir sua boa e sincera vontade de preordenar instrumentos processuais capazes de promover a verdadeira tutela de direitos (WATANABE, 1988, p. 135) e criar, efetivamente, condições de um acesso ao Judiciário, de modo que a garantia maior não seduza apenas enquanto letra morta e fria, relaxada no texto constitucional (BATISTA; FUX, 2001, p. 6).

Mais uma vez vem a lume a Lei $\mathrm{n}^{\circ}$ 9.099/95 que, prevendo um procedimento oral e célere, denominado de sumaríssimo, procura dar uma rápida resposta para os casos que envolvem as chamadas infrações de menor potencial ofensivo. 
Cumpre dizer que tal diferenciação de procedimentos não pode prescindir da admissão de alguns princípios, inclusive de natureza distintas, cujos contornos passam a ser discutidos a seguir.

\subsection{Adoção de princípios diferenciados para causas de particular importância}

A par da criação de métodos alternativos de solução de conflitos e da disponibilização de procedimentos diferenciados para causas de particular importância social, propõe-se, ainda, como diretriz para expansão do efetivo acesso à justiça, a adoção de princípios que possam viabilizar e, melhor, otimizar a atividade do Estado enquanto titular do direito de punir.

Com efeito. Reconhecendo que os princípios têm a vantagem de revelar um norte para todo o sistema, irradiando seus corolários para todas as normas que com ele guardem relação, constatamos que sua eficácia tem o condão de aglutinar valores que, uma vez eleitos, acabam por espelhar a ideologia então assumida pelo Estado, de sorte que se quisermos um ente público comprometido com o efetivo acesso à Justiça, cabe a ele assumir uma postura que valorize e adote meios e instrumentos para alcançar tal escopo.

Como já advertiu Nilo Batista (1996, p. 63),

[...] os princípios básicos, embora reconhecidos ou assimilados pelo direito penal, seja através de norma expressa, seja pelo conteúdo de muitas normas a eles adequadas, não deixam de ter um sentido programático, e aspiram ser a plataforma mínima sobre a qual possa elaborar-se o direito penal de um estado democrático de direito.

Neste contexto é que apontamos a adoção de alguns princípios como ferramenta a ser utilizada na otimização da atividade de pacificação de conflitos, pois, comprometendo o legislador e os aplicadores da lei e, com isso, transitando pela política criminal (BATISTA, 1996, p. 63), passam a ser exigidos e considerados na caracterização das tarefas privativas do Estado.

Enumeramos, a seguir, os mais importantes princípios, aqueles que entendemos sejam essenciais para alcançar a finalidade de viabilizar, auxiliar e otimizar o acesso à justiça.

a) Princípio da Oralidade e seus corolários 
Guardando uma relação direta com o modo pelo qual se desenvolverá o procedimento judicial (CINTRA et al., 1994, p. 323), o Princípio da Oralidade preconiza o predomínio da forma oral no tratamento da causa. Diz-se "predomínio" porque a utilização da escrita (ou outra com tal finalidade) não pode ser descartada, sendo imprescindível para a documentação dos atos praticados.

Segundo Chiovenda (2002, p. 62), o princípio da oralidade não exige em rigor a exclusão da escrita no processo, como o nome poderia levar os desavisados a presumir, uma vez que a escrita, como meio aperfeiçoado, que é, de exprimir o pensamento e de conservarlhe duradouramente a expressão, não pode deixar de ocupar, no processo, o lugar que ocupa em qualquer relação da vida.

Então, se há pouco indicamos o formalismo, o tempo e o custo do processo como barreiras do acesso à justiça, ganha importância a utilidade da oralidade como instrumento apto a simplificar e agilizar o procedimento, reduzindo e concentrando o número de atos judiciais necessários num determinado processo.

Esta adoção da oralidade não implica apenas na prevalência da palavra como meio de expressão combinada com uso de meios escritos de preparação e de documentação, mas pressupõe o necessário reconhecimento de outros princípios que, intimamente ligados, conferem ao procedimento oral seu aspecto particular (CINTRA et al., 1994, p. 324). Referem-se eles aos princípios da concentração, da imediatidade e da identidade física do juiz (CHIOVENDA, 2002, p. 61).

Pelo primeiro, busca-se a concentração do conhecimento da causa num único período (debate) a desenvolver-se numa audiência ou em poucas audiências contíguas (CHIOVENDA, 2002, p. 61); conhece-se da causa em um período breve, em curtos intervalos (CINTRA et al., 1994, p. 324), dando azo ao desaparecimento de numerosas questões alimentadas pelo formalismo do processo e à diminuição de incidentes e impugnações, que passarão a ser decididos prontamente pelo juiz.

Por ser a concentração a principal característica exterior do processo oral, e a que mais influi na abreviação das lides, Chiovenda (2002, p. 66) chega a tomar oralidade como sinônimo de concentração, pois enquanto o processo oral tende a restringir-se a uma ou poucas audiências próximas, nas quais se desenvolvem todas as atividades processuais, o processo escrito, ao contrário, difunde-se numa série indefinida de fases, pouco importando 
que uma atividade se desenvolva mesmo à grande distância de outra, de vez que é apoiado nos atos escritos que o remoto juiz terá, um dia, de julgar.

Desse modo, se a oralidade facilita a rápida cognição da causa, incutindo celeridade ao procedimento, torna-se clara a possibilidade de concentrar-se o maior número de atos num único momento processual. Tal fato não afasta, porém, uma ressalva: a oralidade será tanto mais utilizada e, principalmente, eficaz, quanto menor a necessidade de produção de provas numa lide e mais simples os meios de prova a serem produzidos.

Com efeito. Causas complexas que envolvem um grande volume ou uma variabilidade de meios de prova acabam por pressupor um procedimento que não seja tão abreviado, exigindo documentação da maior parte dos atos praticados e, principalmente, tempo para conhecimento e avaliação da causa pelo juiz e pela parte ex adversa. Não queremos dizer como isso que a cognição no processo oral seja superficial ou que a decisão se demonstre precipitada, mas reconhecer que a oralidade é proveitosa na medida em que causas mais simples passam a contar com um procedimento mais célere para serem resolvidas.

Já lembrou Calamandrei (2003, p. 314) que a rigidez de um procedimento, regulado de modo uniforme para todas as causas possíveis, tem o grande inconveniente de não se prestar a satisfazer simultaneamente a exigência de cuidadosas e exaustivas investigações que se sente, especialmente, em certas causas mais complicadas e difíceis, e a exigência de uma rápida resolução, que predomina nas causas mais simples e urgentes.

Por outro lado, continuando a abordagem dos demais princípios que particularizam a oralidade, temos a imediatidade ou imediação, pela qual se exige o contato direto do juiz com as partes e provas, a fim de que receba, sem intermediários, o material de que se servirá para julgar (CINTRA et al., 1994, p. 324). Note-se que o predomínio da oralidade e o fato da maioria dos atos ser praticada em poucas etapas tornam imprescindível a presença do juiz em tais momentos, conhecendo das provas e argumentos apresentados. Daí porque a identidade física do juiz passa a ser incorporada ao rol de princípios e a constituir um corolário da imediatidade. Salvo casos excepcionais, o magistrado acaba sendo o mesmo do começo ao fim do procedimento, justamente para que o julgamento não seja feito por um juiz que não teve contato direto com os atos processuais (CINTRA et al., 1994, p. 324).

Como advertiu Chiovenda (2002, p. 65-66), a imediação e a oralidade são impraticáveis quando os diversos atos processuais se desenvolvem, a cada trecho, perante pessoas físicas variadas. No processo escrito julga-se sobre o que está escrito, pouco importando que uma atividade seja exercida perante um juiz, outra perante outro e um terceiro 
juiz decida. Segundo ele, "é como se o processo fosse um quadro, uma estátua, um edifício, que um artista pode esboçar e outro concluir, e não uma cadeia de raciocínio, que exige, quanto seja possível, a unidade da pessoa que o realiza".

Automaticamente, perfilhando este entendimento, outro princípio de natureza processual acaba sendo privilegiado. A perspectiva de diminuição de fases e atos processuais leva à economia de tempo e custo e, consequentemente, à aplicação do princípio da economia processual, pelo qual objetiva-se o "máximo resultado com o mínimo emprego possível de atividades processuais" (SANTOS, 1997).

Nessa perspectiva, reconhecemos a importância de atrelar a oralidade aos demais princípios que a viabilizam nos procedimentos que atendam causas de pouca complexidade, concentrando o maior número de atos numa etapa processual e privilegiando o contato direto do juiz com as partes e com as provas. Não se pugna pelo abandono dos procedimentos mais morosos, que privilegiam a escrita, conferem ampla possibilidade de prova às partes e cuja história representa uma conquista da humanidade face à ingerência estatal. Apenas se propõe a simplificação dos procedimentos que, numa razão de proporcionalidade, sejam adequados para entregar, o quanto antes, a prestação da tutela jurisdicional em casos menos complicados. Queremos, enfim, combinara legalidade - a partir da previsão expressa de procedimentos distintos - com a pluralidade das formas - criando alternativas que privilegiem a simplicidade e a oralidade em face da formalidade e da predominância de documentação (CALAMANDREI, 2003, p. 315).

b) Princípio da Intervenção Mínima

Observando as barreiras do acesso à Justiça, apresentadas anteriormente, constata-se que os problemas relativos ao custo, ao tempo, ao formalismo e às peculiaridades das partes foram sempre enfocados levando em consideração o processo, enquanto instrumento de pacificação social.

Partindo-se da verificação de que a prestação jurisdicional é formalista e morosa, envolve gastos para as partes e para o próprio ente público, afugentando o exercício do direito de ação pelos litigantes, foram apontadas algumas diretrizes objetivando viabilizar a atividade estatal, caminhos que devem ser trilhados para otimizar a solução de conflitos no corpo social. 
Ocorre que, em matéria penal, apesar de a aplicação da pena ainda exigir um procedimento previamente ajustado e definido, o acesso à Justiça ganha uma conotação que vai muito além do acesso a um processo rápido e seguro, uma vez que a eficácia da decisão proferida envolve a legitimidade do próprio Direito Penal enquanto instrumento de controle social. Se considerarmos que a impunidade aterroriza a sociedade e cria nesta uma sensação de insegurança, o conceito de Justiça passa necessariamente pela credibilidade do Direito Penal como tutor de direitos fundamentais.

Dessa forma, não basta a garantia de um instrumento célere e desburocratizado de aplicação de pena, se convivemos com um conjunto de normas incriminadoras que têm um valor muito mais simbólico que eficaz no combate à criminalidade. Ainda que o Estado disponibilize meios institucionais ágeis e justos de resolução de conflitos, não serão eles satisfatórios se a tutela pretendida ultrapassar a capacidade do controle penal ou chegar mesmo a desmerecer a sua atenção.

Daí porque propomos, como diretriz para alcançar o acesso à Justiça, a adoção do princípio da intervenção mínima, pelo qual o Direito Penal deve atuar apenas na defesa dos bens jurídicos mais caros da coletividade, tutelando valores que não podem ser eficazmente protegidos de forma menos gravosa. Propõe-se que "o direito penal continue a ser um arquipélago de pequenas ilhas no grande mar do penalmente indiferente" (PRADO, 1999, p. 81).

Esta intervenção mínima encontra amparo em outras características do Direito Penal: a fragmentaridade e a subsidiariedade. Enquanto pela primeira, impõe-se ao Direito Penal uma seleção dos bens jurídicos ofendidos a proteger, pela segunda compete-lhe agir apenas quando uma forma de controle extra-penal se revele ineficiente. Como ressaltou o português Jorge Figueiredo Dias, a limitação da intervenção penal deriva do princípio jurídicoconstitucional da proporcionalidade em sentido amplo, que faz parte dos princípios inerentes ao Estado de Direito. Uma vez que o direito penal utiliza, com o arsenal das suas sanções específicas, os meios mais onerosos para os direitos e as liberdades das pessoas, ele só pode intervir nos casos em que todos ou outros meios da política social, em particular da política jurídica, se revelem insuficientes e inadequados. Quando assim não aconteça aquela intervenção pode e deve ser acusada de contrariedade ao princípio da proporcionalidade, sob a precisa forma de violação do princípio da proibição do excesso (DIAS, 1999, p. 78).

Assim, não só a prévia seleção dos bens jurídicos a serem tutelados pelo Direito Penal, como também a existência de critérios para esta escolha, é essencial para que se 
alcance uma resposta rápida e efetivamente segura aos conflitos desta natureza existentes na sociedade.

O crescente número de normas, objetivando sancionar penalmente interesses que poderiam ser suficientemente protegidos por outros instrumentos jurídicos, ocasiona o inchaço do sistema penal e o desprestígio da pena enquanto reposta estatal ao agente infrator. Se problemas marcadamente econômicos não são resolvidos por soluções meramente legislativas, o Direito Penal, por ser a mais grave forma de ingerência estatal, acaba perdendo seu valor de instrumento de controle social.

\section{CONSIDERAÇÕES FINAIS}

Sob a perspectiva de que o acesso à justiça deve ser ampliado e também aprimorado, a adoção das diretrizes acima expostas torna-se imprescindível na legislação a ser editada. Como toda a persecução penal desenvolve-se sob a intervenção direta do Estado-juiz e se dá nos estritos limites da legalidade, quaisquer ferramentas utilizadas para otimizar a prestação jurisdicional devem, necessariamente, ser previstas em lei.

Tal pressuposto deve ser observado nos casos que envolvam quaisquer modalidades de infrações penais, ainda que de particular importância social. Ainda que se refiram às infrações de menor potencial ofensivo, em que a persecutio criminis admite o trâmite de um devido processo legal consensual, as balizas legais devem se fazer presentes. Mesmo porque a adoção do consenso, entre os interessados, parte da ideia originária de que, em prol da resolução do conflito, seja evitada a demanda ou, ainda que esta ocorra, sejam observados parâmetros mínimos impostos pela lei.

Demonstrando a veracidade de tal afirmação, recorda-se que a criação do instituto da transação penal, a previsão do procedimento sumaríssimo e a criação dos Juizados Especiais Criminais partiram, primeiramente, da Constituição Federal e, somente após a edição da lei federal $n^{\circ}$ 9.099/95, passaram a ter, de fato, aplicabilidade. No âmbito da justiça federal demandaram, inclusive, a edição de uma emenda constitucional (Emenda no 22/1999) e uma legislação própria (Lei n $\left.{ }^{\circ} 10.259 / 2001\right)$.

E não poderia ser diferente. Estando em jogo interesses de natureza indisponível, não poderia o acesso à justiça apresentar-se ao avesso de um figurino legal. Como garantia a réus 
e vítimas, a legitimidade das diretrizes adotadas passa, obrigatoriamente, pelo poder constituinte, originário ou derivado. 


\section{REFERÊNCIAS}

ALVIM, Carreira. Elementos de Teoria Geral do Processo. 7a ed. Rio de Janeiro: Editora Forense, 2000.

BATISTA, Nilo. Introdução Crítica ao Direito Penal Brasileiro. Rio de Janeiro: Revan, 1990, 3a ed., 1996.

BATISTA, Weber Martins; FUX, Luiz. Juizados Especiais Cíveis e Criminais e Suspensão Condicional do Processo. Rio de Janeiro: Forense, 2001.

CALAMANDREI, Piero. Instituições de Direito Processual Civil. Trad. Douglas Dias Ferreira. Vol. I. Campinas - SP: Bookseller, 2003.

CHIOVENDA, Giuseppe. Instituições de Direito Processual Civil. Vol. I. 3a ed. Tradução por Paolo Capitanio. Campinas/SP: Bookseller, 2002.

CAPPELlETTI, Mauro; GARTH, Bryant. Acesso à Justiça. Tradução de Ellen Gracie Northfleet. Porto Alegre: Fabris, 1988.

CINTRA, Antônio Carlos de Araújo; GRINOVER, Ada Pellegrini; DINAMARCO, Cândido Rangel. Teoria Geral do Processo. 10a ed. São Paulo: Malheiros, 1994.

DIAS, Jorge de Figueiredo. Questões Fundamentais de Direito Penal Revisitadas. São Paulo: Editora Revista dos Tribunais, 1999.

FIGUEIRA JÚNIOR, Joel Dias. Arbitragem, Jurisdição e Execução. São Paulo: Editora Revista dos Tribunais, 1999.

GRINOVER, Ada Pellegrini. A Conciliação Extrajudicial no Quadro Participativo. In Participação e Processo. Coordenação de Ada Pellegrini Grinover, Cândido Rangel Dinamarco e Kazuo Watanabe. São Paulo: Editora Revista dos Tribunais, 1988.

MIRABETE, Júlio Fabbrini. Juizados Especiais Criminais. São Paulo: Atlas, 2002.

MONTORO, André Franco. Introdução à Ciência do Direito. Vol. I. 8a ed. São Paulo: Editora revista dos Tribunais, 1978.

MORAES, Silvana Campos. Juizado de Pequenas Causas. São Paulo: Editora Revista dos Tribunais, 1991.

NALINI, José Renato. O Juiz e o Acesso à Justiça. São Paulo: Editora Revista dos Tribunais, 1994.

PORTANOVA, Rui. Princípios do Processo Civil. 4a.ed. Porto Alegre: Livraria do Advogado, 2002. 
PRADO, Luiz Régis. Curso de Direito Penal Brasileiro - Parte Geral. São Paulo: Editora Revista dos Tribunais, 1999.

SANTOS, Moacyr Amaral. Primeiras Linhas de Direito Processual Civil. 18 ed. Vol. 2. São Paulo: Saraiva, 1997.

SILVA, Marco Antônio Marques da. Acesso à Justiça Penal e Estado Democrático de Direito. São Paulo: Juarez de Oliveira, 2001.

TUCCI, José Rogério Cruz e. Tempo e Processo: uma análise empírica das repercussões do tempo na fenomenologia processual (civil e penal). São Paulo: Editora Revista dos Tribunais, 1997.

WATANABE, Kazuo. Acesso à Justiça e Sociedade Moderna. In Participação e Processo. São Paulo: Editora Revista dos Tribunais, 1988. 